\title{
DESIGN AND DEVELOPMENT OF A LABORATORY FOR THE STUDY OF PEMFC SYSTEM FOR MARINE APPLICATIONS
}

\author{
Gerardo Borgogna ${ }^{1 *}$, Enrico Speranza ${ }^{1}$, Thomas Lamberti $^{2 \dagger}$, Alberto Nicola Traverso ${ }^{2}$, \\ Loredana Magistri ${ }^{2}$, Eleonora Gadducci ${ }^{2}$, Aristide Fausto Massardo ${ }^{2}$, Paolo Olivieri ${ }^{3}$ \\ ${ }^{1}$ Fincantieri S.p.a., via Cipro 11, 16129 Genova, Italy \\ ${ }^{2}$ DIME-TPG University of Genoa, via Montallallegro 1, 16145 Genova, Italy \\ ${ }^{3}$ H2Boat S.c.a.r.l., via G.B. Magnaghi 3/11d, 16129 Genova, Italy
}

\begin{abstract}
Climate change is driving the introduction of strict emission limits in the shipping sector favoring the introduction of alternative fuels, among which hydrogen. While the storage energy density of this energy vector is a key challenge that makes way to a variety of different solutions, from fossil fuel reformers to sodium borohydride systems, fuel cell systems are generally considered among the future ideal energy converters. Nevertheless very few fuel cell marine applications are available worldwide, none of them is related to a ship application, mainly because of the high power requirements. Fuel cells are relatively new in the shipping sector, up to now no civil industrial system has been commercialized yet while military applications rely only on the U212 submarine of the Italian and German Navy. The lack of favorable niche markets coupled with the strong conservative and traditional design principles held back the investment for optimized marine systems. For this reason, present and past projects made use of conveniently adapted automotive technologies into pilot demos, with particular focus on Proton Exchange Membrane Fuel Cell (PEMFC). However, ships requirements are largely different from automotive ones, not only for the power size that are in the range of MWs instead of kWs. On the other side, in order to take advantage of large scale production as well as of the modularity of fuel cell technology, the integrations of automotive or stationary based fuel cell subsystems, already available on the market, inside a dedicate modular marine system seems to be the solution pursued by many shipbuilders and contemplated by regulatory authorities. In hybrid system configurations, fuel cells are considered in combinations with batteries, another important technology under development, in order to take advantage of the superior energy performances of fuel cell systems and the highly power discharge dynamics of batteries. The need of fuel cell power systems for ships is pushing towards the creation of knowledge that requires laboratories able to challenge the abovementioned issues in order to give answers to shipbuilders and at a lower level also to rule makers.
\end{abstract}

\footnotetext{
* Corresponding author: gerardo.borgogna@fincantieri.it

${ }^{\dagger}$ Corresponding author: thomas.lamberti@edu.unige.it
} 


\section{Nomenclature}

Table 1. Nomenclature table.

\begin{tabular}{|c|c|}
\hline BoP & Balance of Plant \\
\hline CVM & Control Voltage Monitoring \\
\hline DER & Distributed Energy Resources \\
\hline DMFC & Direct Methanol Fuel Cell \\
\hline ECA & Emission Control Area \\
\hline E-Hub & Energy Hub \\
\hline EMSA & European Maritime Safety Agency \\
\hline FC & Fuel Cell \\
\hline FCS & Fuel Cell System \\
\hline ICE & Internal Combustion Engine \\
\hline IMO & International Maritime Organization \\
\hline MFC & Mass Flow Controller \\
\hline MH & Metal Hydride \\
\hline MSC & Maritime Safety Committee \\
\hline OEM & Original Equipment Manufacturer \\
\hline PEMFC & Proton Exchange Membrane Fuel \\
\hline SOA & Cell \\
\hline SOFC & State Of the Art \\
\hline
\end{tabular}

\section{Introduction}

Regulations are setting to change common practice in marine power generation under the pressure of pollutant emissions reduction. The International Maritime Organization (IMO) is already imposing tight emission limits on Particulate Matter, $\mathrm{SO}_{\mathrm{x}}$ and $\mathrm{NO}_{\mathrm{x}}$ that for emission control areas (ECAs) are difficult if not impossible to be meet with traditional diesel engines and bunker fuels [1]. Fuel cell systems (FCS) are considered among the most promisign technologies able to reduce pollutants emissions and increase efficiencies [2]. The shipping fuel cell (FC) propulsion technology state of the art (SOA) is poor due to variuous reasons, among which the absence of prescriptive rules for the installation of alternative systems and lack of regulations on ships environmental impact, in particular on greeenhouse gasses (GHGs) [3][4]. A recent review of fuel cell systems for marine applications [5] showed the potentials of this technology coupled with different fuels while the European Maritime Safety Agency (EMSA) commissioned to DNV-GL a study [6] on the use of fuel cell in shipping that further distinguished the most suitable fuel cell technology for marine applications among which PEMFC result to be the most mature one. In parallel, the TESEO project "High Efficiency Technologies For On-Board Energy And Environmental Sustainability" [7] investigated among all the use of PEMFC for the development and demonstration of an electrical generator of $260 \mathrm{~kW}$ output power for marine application, that has been designed and built by Fincantieri with the technical support of the University of Genoa. Due to the relevance of the topic, the prototype has been designed inside a container with a high flexible electric architecture to permit the 
future continuation of the studies. The exploitaion of the system research potential required the outfitting of a dedicated laboratory that has been modeled considering past experiences, technology SOA, ships and rule requirements.

The HI-SEA (Hydrogen Initiative for Sustainable Energy Application) Joint Laboratory represents the first large scale PEMFC test rig especially dedicated to the study of FC application onboard ships and for marine application in general. The goal of the laboratory is to define the best design for a modular FC system for ship application able to guarantee the maximum life spam of FC stacks without omit performance.

\section{Fuel Cell System Test Rig}

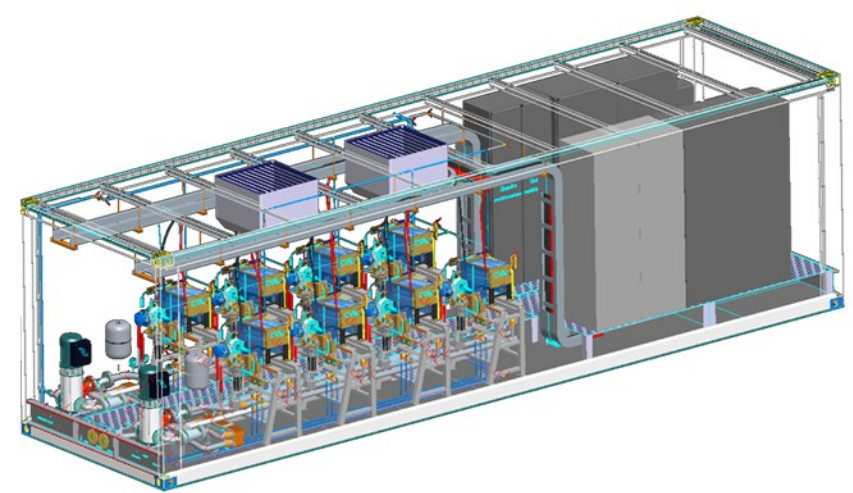

Figure 1. PEMFC FCS test rig

The first and main objective of the FCS test rig, developed during the TESEO Project [7] was the definition of the best design and size of a modular PEMFC system for ship application. The goal was achieved towards the development of a high flexible system able to demonstrate the feasibility of the technology in a simulated relevant environment, namely a ship fuel cell room. Moreover, the test rig has been designed in order to be easily transported (inside a $30 \mathrm{ft}$ container, Figure 1) and integrated into a laboratory able to simulate a ship infrastructure. In order to permit the investigation of the best electric and fluid architecture a mixed configuration has been adopted connecting two symmetrical branches composed by 4 stacks in series, Figure 2. Each stack (L1) has been integrated with BoP components that integrate also an air Mass Flow Controller (MFC) able to control the air flow in order to simulate the behavior of different blowers specification (L2). Each branch is autonomous, with dedicated DC/DC converter and cooling system (L3). The chosen technology for the test rig is the commercial PEMFC, characterized by metallic bipolar plates and open flow field with $30 \mathrm{~kW}$ of nominal power at $1 \mathrm{~A} / \mathrm{cm}^{2}$. 


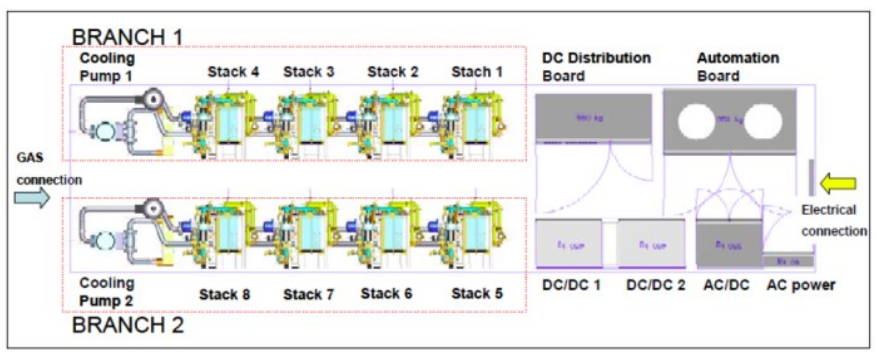

Figure 2. FCS test rig configuration

The DC/DC converter is able to work with the tension of 3 or 4 connected stacks enabling the simulation of a single stack fault on each branch permitting the control of the output tension and current. The DC/DC can also be bypassed in order to directly connect the FC to the electric load. Moreover, the $60 \mathrm{~kW}$ AC/DC rectifier together with the controllable electric load permit the simulation of any kind of battery packs, enabling the assessment of the optimum balance between FC and battery dimension as a function of the operational profile and the optimal integration of PEMFCs in a DC grid. Different operational profiles can be tested to investigate the possibility to utilizing PEMFC system to power only auxiliaries or propulsion.

\section{Maturated experience}

Few tests have been conducted during the TESEO project due to time constraints. No significant data have been published but important experience have been registered and later used to design the HI-SEA laboratory, in particular for the definition of important parameters to be supervised and of safe control procedures. At the end of the project, the following observation were made:

- Cooling water conductivity. After the system shot down the cooling water was analyzed and found with conductivity values higher than the accepted value, 5 $\mu \mathrm{S} / \mathrm{cm}$. The problem was related to the use of an inappropriate glycol.

- Standby monitoring (air to the cell). The lack of air flow measure of the stacks didn't permit the identification of a faulty air MFC.

- FC module insertion in series. When a series of fuel cell stacks is supplying high currents, the insertion of a stack has to be avoided in order to prevent possible FC damage.

- Purge system temporization. If the purge pipes of various operating stacks is combined into a single pipe, the former should be properly dimensioned or the stacks purge time should be correctly synchronized in order to avoid the counter pressure.

- DC/DC control. A properly defined control is required to permit the simultaneous current supply by systems connected in parallel.

- Electric load control for simulation. The electric load resistance should be properly sized and controlled in order to simulate an electric load without falling into control interference between the DC/DC converter and the electric load. 
Moreover a number of parameters have been monitored in the new installation in order to enhance the interpretation of the phenomena.

\section{HI-SEA joint laboratory}

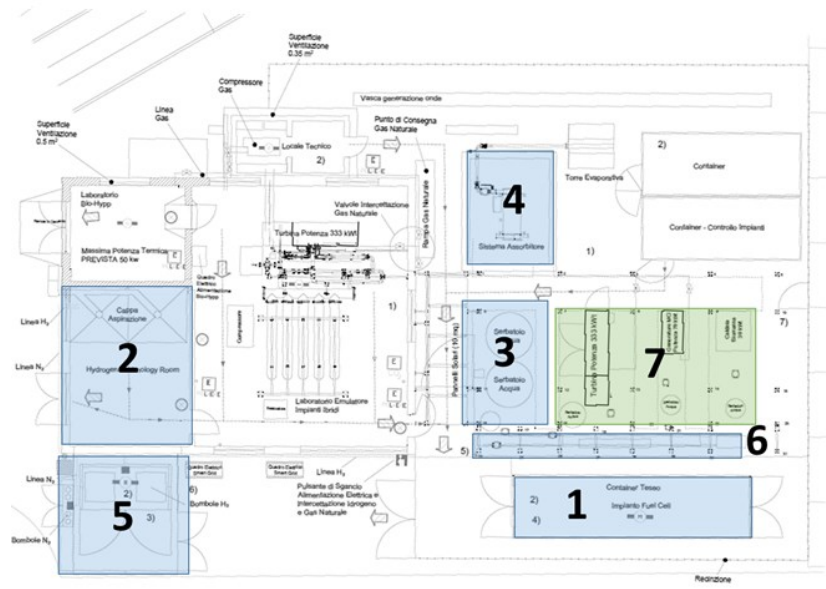

Figure 3. HI-SEA Laboratory plant

The HI-SEA laboratory presents a unique presence of facilities that make it suitable for the study of ships power generator systems. Referring to Figure 3: 1. PEMFC power systems, with $260 \mathrm{~kW}$; 2. Dedicated space for test and analysis of $30 \mathrm{~kW}$ stacks and Metal Hydride $(\mathrm{MH})$ hydrogen storage tanks; 3. Large heat storage systems; 4. Absorber chiller of 100 kWth; 5. Hydrogen storage; 6. Water cooling system; 7. Lab scale micro grid E-Hub [8], composed by a $100 \mathrm{kWe}$ micro turbine, a $20 \mathrm{kWe}$ cogenerated ICE and a $1 \mathrm{kWe}$ photovoltaic solar panel system. The laboratory gives the opportunity to study the behavior of the PEMFC systems in a grid with different sources of electrical and thermal power, enabling the development of design tools for smart grid controls. The presence of water storage systems with temperatures and flows measurement will enable to assess the potentiality of the PEMFC system for cogeneration. Moreover, the absorber chiller working temperature comply with the thermal output of the PEMFC and will permit to test at a real system size the coupling of the systems, an important achievement for the reduction of onboard air conditioning energy consumption. Finally, the equipped space will permit tests and analysis of single FC stacks and of Metal Hydride tanks, with the possibility to develop an optimum thermal integration between them. In the following a list of potential analysis that can be developed in the laboratory is reported:

- Definition of FCS marine requirements and related test protocols;

- ESS coupling (with FCS) and sizing;

- Co-generation;

- Tri-generation;

- Dynamic simulations;

- Diagnostic database and simulations;

- Reliability engineering;

- Design specification of case studies;

- Optimization;

- Safety;

- FC lifetime; 
- System design and operation;

- Scientific dissemination;

- Training.

\section{Fuel Cell Systems for ships}

On board ships electrical power is mainly used for auxiliaries, but the tendency towards the use of electricity for propulsion is increasing [9]. The majority of ships produce electricity using diesel generators (gen-sets) localized in few engine rooms that are characterized by higher efficiencies at partial load, while power is delivered to the users towards long cables penalized by transport losses. The traditional design approach allow the delimitations of zones where safety related issues like fire can be identified as a significant hazard [10][11]. At the same time, all outlet gases and inlet ventilation piping and casings are confined in a few astern zones. Conversely, fuel cells like batteries are modular systems that are not dependent on the size of the module and presents higher efficiency at partial load. As a result, FCSs can be distributed over the ship, increasing redundancy, reducing electricity transport costs and enabling Distributed Energy Resources (DER) concepts.

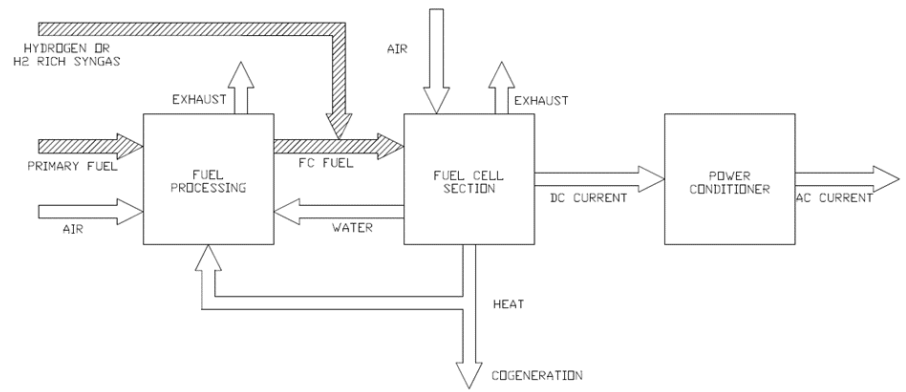

Figure 4. General scheme of FCS

For these reasons the definition of the fuel cell power installation is fundamental. Indeed, the IMO Maritime Safety Committee (MSC) is presently working to the definition of Part E of the IGF code [12] dedicated to the use of fuel cell systems. FCSs should reflect present and future regulations integrating all the system components in a safe and effective way in order to comply with the above-mentioned situation. A FCS is generally composed by three main parts: the fuel processor, the fuel cell power section, the power conditioner [13].

A) REFTRMER UNIT
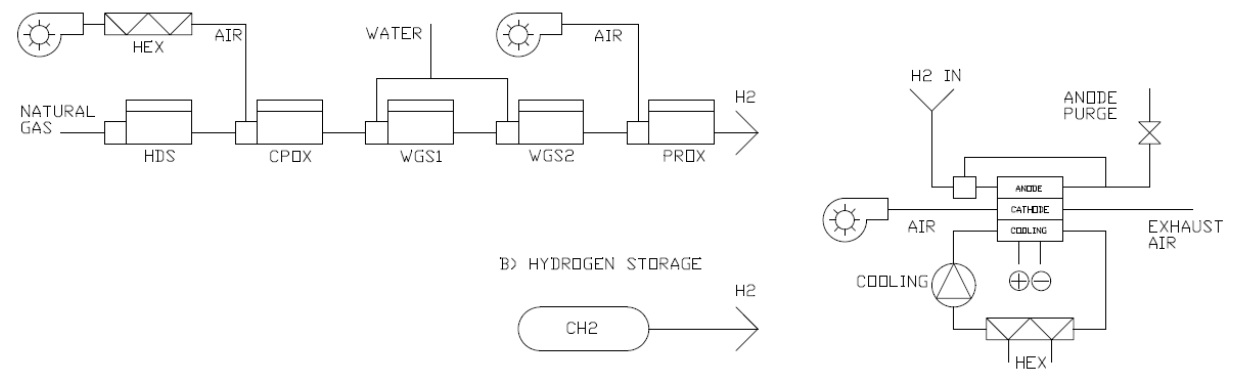

Figure 5. PEMFC system P\&ID: a) Reformer unit; b) Hydrogen storage 
Figure 4 shows a scheme with the fuel energy flows. Not all the system require the fuel cell processor nor the fuel processor unit is equal for any kind of fuel cells, it depends on the primary fuel and the fuel cell electrolyte. Therefore, two configuration can be derived, the first considers the use of a primary fuel that requires a fuel processor, while the second one considers the direct use of the fuel inside the fuel cell power section. The results of previous studies [6][7] brought to the choice to focus the analysis on the marine application of PEM technology. Figure 5-a shows a PEM FCS with fuel processing unit [13], in contrast with the traditional scheme of a PEM FCS directly fed with pure hydrogen (Figure 5-b). The schemes highlight the large differences between the systems. The differences are even more evident in the case of HTPEM FCS, that are able to be thermally coupled with low temperature fuel reformers as Methanol reformer [14]. The direct output of these considerations is the necessity to optimize the system design on the base of the ship requirements, fuel cell typology and energy vector storage technology.

\section{Conclusions}

Recent announcements from different ship owners, the strong commitment by IMO in the development of FCs and alternative fuels codes combined with the increasing public pressure on global warming and environmental issues represent the signal that the momentum for the introduction of FCS on board ships is growing. Past projects experiences, marine, mechanical and electric engineering competences are merging in the industrial and academic fields all around Europe, from Norway to Italy. The HI-SEA laboratory represents an important step by private and public entities towards the development of the knowledge required for the design, test and installations of the marine FCSs of the future, starting from PEMFC systems. The paper shows the path that was followed to develop the laboratory, with a focus on the FCS architecture, a fundamental study necessary for the understanding of the system. Moreover a resume of experiences is reported together with a list of studies that the authors consider important for the development of marine FCS.

\section{Acknowledgment}

The PEMFC system was built in 2015 as result of the project named "TESEO, co-financed by the Italian Research and University Minister (MIUR) under the PON02_00655 framework, in collaboration with CNR-ITAE of Messina. The HI-SEA Joint Laboratory is funded by Fincantieri spa and will be launched during 2018.

\section{References}

1. S. Brynolf, M. Magnusson, E. Fridell, K. Andersson, Compliance possibilities for the future ECA regulations through the use of abatement technologies or change of fuels, Transp. Res. Part D Transp. Environ. 28, (2014).

2. A.B. Stambouli, E. Traversa, Fuel cells, an alternative to standard sources of energy, Renew. Sustain. Energy Rev. 6 (3), (2002).

3. V. Eyring, H. Kohler, A. Lauer, B. Lemper, Emissions from international shipping: 2. impact of future technologies on scenarios until 2050, J. Geophys. Res. Atmos. 110 (D17), (2005). 
4. D. Gerard, L.B. Lave, Implementing technology-forcing policies: the 1970 clean air act amendments and the introduction of advanced automotive emissions controls in the United States, Technol. Forecast. Soc. Change 72 (7), (2005).

5. L. van Biert, M. Godjevac, K. Visser, P.V. Aravind, A review of fuel cell systems for maritime applications, Journal of Power Sources, Volume 327, Pages 345-364, (2016).

6. Tomas Tronstad, Hanne Høgmoen Åstrand, Gerd Petra Haugom, Lars Langfeldt, Study on the use of fuel cells in shipping, EMSA European Maritime Safety Agency Report, (2017).

7. TESEO Project, High Efficiency Technologies For On-Board Energy And Environmental Sustainability, PON02_00153_2939517, (2012-2015).

8. M.L. Ferrari, M. Pascenti, A. Traverso, A.F. Massardo, An experimental facility for tests on distributed generation systems. International Conference on Applied Energy, Suzhou, China, Paper ID: ICAE2012-A10204, (2012).

9. T.A. Rodrigues, G.S. Neves, L.C.S. Gouveia, M.A. Abi-Ramia, M.Z. Fortes, S. Gomes, Impact of electric propulsion on the electric power quality of vessels, Electric Power Systems Research, Volume 155, Pages 350-362, (2018).

10. R.D. Geertsma, R.R. Negenborn, K. Visser, J.J. Hopman, "Design and control of hybrid power and propulsion systems for smart ships: A review of developments", Applied Energy 194, 30-54, (2017).

11. D.J Eyres, G.J Bruce, “Ship Construction”, Elsevier (2012).

12. IMO, International Code of Safety for Ship Using Gases or Other Low-flashpoint Fuels (IGF Code), RESOLUTION MSC.391(95), (2017).

13. E\&G Technical Services, U.S. Department of Energy, Fuel Cell Handbook (Seventh Edition), (2004).

14. Suthida Authayanun, Dang Saebea, Yaneeporn Patcharavorachot, Amornchai Arpornwichanop, Evaluation of an integrated methane autothermal reforming and high-temperature proton exchange membrane fuel cell system, Energy, Volume 80, Pages 331-339, (2015). 